\title{
BOOKS, BOOK AND \\ PRINTING TRADE
}

139 INDIAN BOOK INDUSTRY: Book Production and Distribution Journal. Sterling Publishers (P) Ltd, AB/9, Safdarjang Enclave, New Delhi 16. 12. Annual £4.

"The only monthly linking the activities of Publishers, Booksellers, Librarians, Scholars, Research bodies, Universities and other trades and industries connected with the production and distribution of books, i.e. paper, printing machinery etc etc."

140 INDIAN PRINT AND PAPER: The Eastern Journal for Printers and Papermakers. 1, India Exchange Place, Calcutta 1. 4. Annual $27 \frac{1}{2} \mathrm{p}$.

"A journal for printers, papermakers and those interested in print." "Its aim is to furnish the latest and most authoritative information on all matters relating to printing and its allied industries."

141 INDIAN PRINTER AND STATIONER: A Monthly Journal devoted entirely to the Printing Trade. Kitabghar Printery, Rajkot, India. 12. Annual Rs 1.

Trade journal.

142 PAPERPRINTPACK INDIA - see Paper

143 SINGAPORE BOOK WORLD. Chopmer Enterprises, 47, The Arcade, Raffles Place, Singapore 1. National Book Development Council of Singapore. 2. Gratis.

Articles on aspects of book development in Singapore. Book reviews. 